\title{
Multiobjective Optimization of Cable Forces and Counterweights for Universal Cable-Stayed Bridges
}

\author{
Zhangming Wang, ${ }^{1}$ Nan Zhang $\mathbb{D D}^{1}{ }^{1}$ Xianting Du, ${ }^{1}$ Shilei Wang, ${ }^{2}$ and Qikai Sun ${ }^{1}$ \\ ${ }^{1}$ Department of Civil Engineering, Beijing Jiaotong University, Beijing 100044, China \\ ${ }^{2}$ Infrastructure Inspection Research Institute, China Academy of Railway Sciences Group Co., Ltd., Beijing 100081, China
}

Correspondence should be addressed to Nan Zhang; nzhang@bjtu.edu.cn

Received 14 October 2020; Revised 18 December 2020; Accepted 2 January 2021; Published 15 January 2021

Academic Editor: Bin Yu

Copyright (c) 2021 Zhangming Wang et al. This is an open access article distributed under the Creative Commons Attribution License, which permits unrestricted use, distribution, and reproduction in any medium, provided the original work is properly cited.

\begin{abstract}
In cable-stayed bridges, especially asymmetric bridges, counterweights are always made to work together with cable pretension forces to get a reasonable finished state. To solve the optimization problem of the cable-stayed bridge considering the counterweights, the integrated optimization method (IOM) for estimating cable forces and counterweights is proposed. In this method, the counterweights are proposed to act on the anchor points. After that, the summary of the minimum weighted total bending energy and the summary of the counterweights are considered as two objective functions of a multiobjective problem. Finally, the dynamic weighted coefficient method is used to solve this problem and realize the Pareto solution set. IOM presents detailed procedures in a simple numerical model and is then applied to the Yong-ding special-shaped cable-stayed bridge. The results show that not only IOM can realize the priority selection of the loading position of the counterweights but also get a better reasonable finish state because of the introduction of the counterweight dimension; the dynamic weighted coefficient method can quickly find the Pareto optimal solution set and be further screened by decision-makers; counterweight is very helpful to reduce torsion and other spatial effects in cable-stayed bridges. IOM can be used as a universal optimization method for cable-stayed bridges.
\end{abstract}

\section{Introduction}

Cable-stayed bridges are statically indeterminate structures, and their structural behavior is greatly influenced by cable pretension forces. Therefore, the determination of cable pretension forces is critical in the design procedure.

However, with the development of cable-stayed bridges in recent years toward large-span, spatialization and artistry, and various cable-stayed bridges of strange shapes appear more and more frequently [1-3]. Sometimes the reasonable finish state cannot be achieved by adjusting the cable force alone; the counterweight is used to work together with cable pretension forces [4]. For example, in long-span cablestayed bridges, the side spans often use concrete beams that are heavier than the midspan steel box girder or add extra counterweights to balance the self-weight of the main span [5]. Besides, curved bridges [1] or special-shaped bridges $[2,3]$ which are asymmetrical across the bridge direction, counterweights are often used to control the asymmetric effect of the structure in the transverse direction.

There have been several methods proposed in the literature for determining pretension forces of cable-stayed bridges $[6,7]$, which can be divided into four types: the optimization methods for specified structural conditions, the minimum bending energy methods, the unit load methods, and the mathematical optimization methods.

The optimization method of the specified structure state takes the internal force and displacement of the cable-stayed bridge structure as the optimization objective, and the constraints are usually set as a specified value or feasible region. Wang et al. [8] aimed at zero vertical displacements of anchor points and proposed the zero displacement method of cable-stayed bridges; Chen et al. [9] proposed the force equilibrium method later. In this method, the additional bending moments of the girder can be considered, so it is more rational than the zero displacement method. The 
optimization goal and the mechanical concept of these methods are clear, and the calculation process is also convenient. However, it cannot consider the forces and deformations of pylon and girder at the same time.

The objective function of the bending energy minimum method comprehensively considers the force and deformation of the main girder and the bridge tower, which reflects the essential characteristics of cable force optimization and can obtain more reasonable optimization results. Based on the theory of minimum bending energy, Liang et al. [10] proposed a practical method (PM) of estimating pretension force, which is widely used in China. However, PM can only play a role in the bridge preliminary design stage because of the absence of constraints. Sung et al. [2] used the bending energy minimum method with constraints to derive the objective functions as a quadratic form of the posttensioning cable forces, and the applications of this method on the Mau-Lo Hsi cable-stayed bridge showed great applicability for asymmetric cable-stayed bridges.

The unit load method [11] is the link that establishes the relationship between the cable force and the objective function, and it is also a comprehensive cable force optimization tool. Sung et al. [2], Li et al. [12], and Hassan et al. [13] used the unit load method to build the mathematical optimization model of the bending energy minimum or the summary of displacement.

After building the model, the mathematical optimization methods can play their role. They can select the objective function, constraint conditions and optimization algorithm according to the structural characteristics of different types of cable-stayed bridges, and the results obtained can also take into account the forces and deformations of each member of the cable-stayed bridge and have strong applicability. Ha et al. [14] used the genetic algorithm (GA) to optimum stay cables of steel cable-stayed bridge considering nonlinear inelastic characteristics (single-objective). Hassan et al. [13] took the shape of the structure as the goal and achieved multiobjective optimization by GA using the weighted coefficient method $[15,16]$. The disadvantages of this method are obvious. (1) The weighted coefficient is sensitive and requires certain experience to determine. (2) The absence of Pareto solutions makes it still a single-objective optimization. Some more well-known optimization techniques also include the simulated annealing algorithm [1, 17], the particle swarm algorithm [18, 19]. They are used in the field of structural optimization design due to their better global convergence, versatility, and ease of parallel processing. Despite these advantages, when facing multiobjective optimization, these methods are either too expensive to learn or are not real multiobjective optimization.

Lee et al. [20] took into account the influence of the counterweights but did not involve the calculation of the counterweights. Song et al. [5] took a long-span cable-stayed bridge as an example, assumed that the side span counterweights was a continuous uniform load, and used the hillclimbing algorithm to calculate the bridge cable force considering the counterweights. The assumption of continuous uniform distribution of the weight of this method limits its application scenarios. Besides, the hill-climbing algorithm is inefficient and easy to fall into local convergence. So far, the optimization of cable-stayed bridges with counterweights has not been studied systematically and effectively. Most engineers still use manual iteration for multiple trial calculations to coordinate and optimize the initial tension and counterweight. This method has low work efficiency and unstable target state effects and cannot fully exploit the performance of cable-stayed bridges.

Based on the above research, this paper proposes a universal integrated optimization method (IOM) that can consider counterweights and suitable for asymmetric cablestayed bridges. Firstly, the optimization scheme of the algorithm is elaborated. Secondly, the calculation process of the algorithm is demonstrated through a numerical model of a cable-stayed bridge that is asymmetric along the bridge direction and is compared and studied with the practical method of bending minimum energy method (PM) and coordinated optimization method without considering counterweights (COM). Finally, IOM is applied to the highly asymmetrical Yong-ding River special-shaped cable-stayed bridge, and the problems such as counterweights distribution and space torsion have been studied and demonstrated in detail.

\section{Optimization Formulation}

2.1. Design Variables. The reasonable finished dead state of cable-stayed bridges is generally achieved by adjusting the pretension force to optimize the objective function. As shown in Figure 1, without considering the counterweights, the function can be regarded as an optimization curve on the plane $W=0$, and its minimum value is recorded as the local best point $A$ on the plane. However, when counting the counterweights, the objective function can be expanded to a $3 \mathrm{D}$ optimization surface including the optimization curve. The lowest point on the optimized surface can be credited as the space global best point $B$. It is easy to know that $f(B) \leq f$ (A).

In the beginning, the designer did not know where the counterweights should be arranged. To solve this problem, we can assume that the counterweights act on all anchor points and the number of counterweights corresponds to the number of cables. After completing the solution, the anchor point can be considered as unweighted as long as the result of calculated Wi is very small or zero. At first, the design variables can be expressed as

$$
X=\left[T_{1}, T_{2}, \ldots, T_{n}, W_{1}, W_{2}, \ldots, W_{n}\right]^{T},
$$

where $T$ is the cable pretension force, $W$ is the counterweight on the anchor point, and $n$ is the number of cables.

2.2. Objective Function. The objective function determines the reasonable finish state of the cable-stayed bridge. The bending energy minimum method not only considers the internal force of the main girder and the bridge tower comprehensively but also reflects the essential characteristics of cable force optimization. Summary of squares of bending moment of each element is defined as the bending energy, which can be expressed by arrays as 


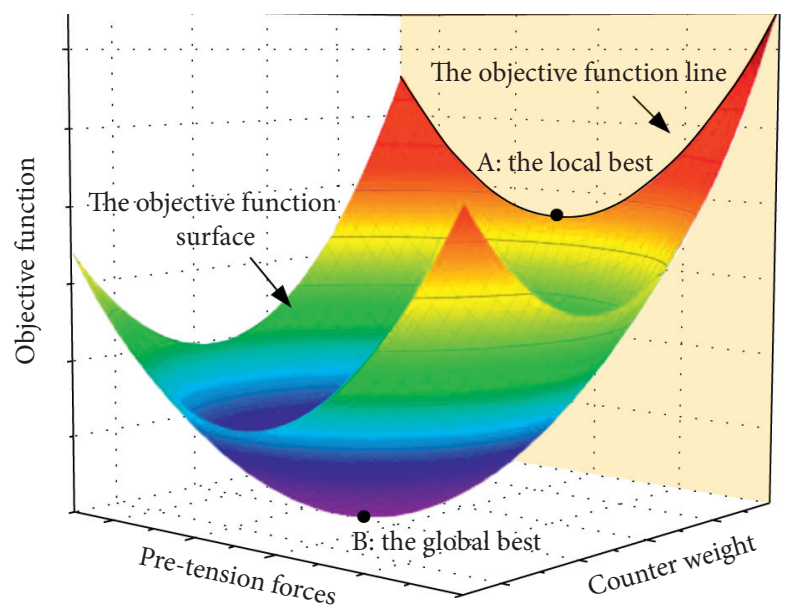

Figure 1: Schematic diagram of IOM.

$$
U=\left\{M_{L}\right\}^{T}[B]\left\{M_{L}\right\}+\left\{M_{R}\right\}^{T}[B]\left\{M_{R}\right\}
$$

where $B=\operatorname{diag}\left(L_{i} / 4 E_{i} I_{i}\right), i=1,2,3, \cdots, n$. For element $i, L_{i}$ and $I_{i}$ are the length and the moment of inertia of the section, respectively. $E_{i}$ is Young's modulus of materials. The introduction of stiffness $B$ can allocate bending moments according to the bearing capacity of different elements so that the stress of each element can be kept at the same basically. $\left\{M_{L}\right\}$ is the bending moment vector at the left end of the element under the dead load state. $\left\{M_{R}\right\}$ is the bending moment vector at the right end of the element under the dead load state. It can be sorted out as follows:

$$
U=X^{T} H X+2 c^{T} X+K,
$$

where $\quad H=C_{\mathrm{ML}}^{T} B C_{\mathrm{ML}}+C_{\mathrm{MR}}^{T} B C_{\mathrm{MR}}, \quad c^{T}=M_{\mathrm{LD}}^{T} B C_{\mathrm{ML}}$ $+M_{\mathrm{RD}}^{T} B C_{\mathrm{MR}}$, and $K=M_{\mathrm{LD}}^{T} B M_{\mathrm{LD}}+M_{\mathrm{RD}}^{T} B M_{\mathrm{RD}} \cdot C_{\mathrm{ML}}$ and $C_{\mathrm{MR}}$ represent the influence matrix of the left and right bending moments of the element under the action of the unit variable $X ; M_{\mathrm{LD}}$ and $M_{\mathrm{RD}}$ represent the bending moment vectors at the left and right end of the element under the dead load of the reasonable finish state, respectively.

It is not hard to see that different anchor points have different efficiencies in changing the major objective function. The designer hopes that a reasonable bridge state can be obtained by adding a small amount of counterweights to some of the best efficient anchor points. The summary of counterweights $S=\sum_{i=1}^{n} W_{i}$ can be set as the secondary objective function so that limited counterweights will be biased towards efficient anchor points; the others will be set as zero automatically. In this way, the number of counterweights will also be restricted at the same time. The expression form of the influence matrix is

$$
S=\left[O_{1 \times n}, I_{1 \times n}\right] X
$$

2.3. Constraints. The purpose of setting constraints is to limit the mathematical solution of the design variables within the allowable engineering range. In the process of determining the reasonable finish state of various cablestayed bridges, there are five possible constraints.

\subsubsection{Constraint of Cable Forces.}

$$
T_{\min } \leq T_{D}+C_{X} X \leq T_{\max }
$$

where $T_{\min }$ is the lower limit value of cable forces, $T_{\max }$ is the upper limit value of cable forces, and $T_{D}$ is the cable force under the dead load; $C_{X}$ is the influence matrix of cable force under unit cable force and counterweight.

2.3.2. Constraint of Uniformity of Cable Forces. If only the cable force constraint conditions are used for optimization, the resulting cable force distribution may be very uneven. It is necessary to introduce the cable force distribution of adjacent stay cables as a cable force uniformity condition. Suppose the cable forces of three adjacent stay cables on the same cable plane are $T_{i-1}, T_{i}$, and $T_{i+1}$. The uniformity of cable forces is defined as $Z_{i}=\left(T_{i-1}+T_{i+1} / 2\right)-T_{i},(i=2, \ldots, n-1)$, and the expression form of the influence matrix is $Z=\left[D, O_{(n-2) \times n}\right] X$, where

$$
D=\left[\begin{array}{cccccc}
0.5 & 1 & 0.5 & 0 & \cdots & 0 \\
0 & 0.5 & 1 & 0.5 & \cdots & 0 \\
\vdots & \vdots & \vdots & \vdots & \ddots & \vdots \\
0 & 0 & 0 & 0.5 & 1 & 0.5
\end{array}\right]_{(n-2, n)}
$$

The constraint of uniformity of cable forces is defined as

$$
z_{\min } I_{(n-2) \times 1} \leq\left[D, 0_{(n-2) \times n}\right] X \leq z_{\max } I_{(n-2) \times 1},
$$

where $z_{\min }$ and $z_{\max }$ are the minimum and maximum values of uniformity of cable forces. 
2.3.3. Constraint of Displacement. According to the influence of dead load on the displacement, the displacement constraint condition of structure can be expressed as

$$
\delta_{\min } \leq \delta_{D}+C_{\delta} X \leq \delta_{\max } .
$$

$\delta_{\min }, \delta_{\max }$ is the lower and upper limit of displacement; $\delta_{D}$ is the displacement of the structure under the dead load; $C_{\delta}$ is the influence matrix of structural displacement under unit cable force and counterweight.

2.3.4. Constraint of Internal Force. The introduction of the linear stiffness $B$ in the main objective function can distribute the appropriate bending moment according to the bearing capacity of different elements, so that the maximum stress of each element is kept at a certain level. Therefore, it is not necessary to limit the internal force for the whole structure. Only in some cases, it may be necessary to control the internal force for some special sections, and the constraint conditions can be set as

$$
M_{\min } \leq M_{D}+M_{X} X \leq M_{\max },
$$

where $M_{\min }$ is the lower limit of internal force; $M_{\max }$ is the upper limit of internal force; $M_{D}$ is the internal force of structure under the dead load; and $M_{X}$ is the influence matrix of the internal force of the structure under unit cable force and counterweight.

2.3.5. Constraint of Relative Displacement. For specialshaped cable-stayed bridges, such as the double girders model of the Yong-ding bridge in Section Engineering Application, in order to prevent excessive torsional deformation of the structure in the transverse direction, the difference of vertical displacement of the two girders still needs to be limited, and the difference of displacement along the bridge direction of two limbs of the tower can also be considered in the same way. It can be expressed as the structural relative displacement as follows:

$$
\Delta \delta_{\min } \leq \Delta \delta_{D}+\Delta C_{\delta} X \leq \Delta \delta_{\max }
$$

where $\Delta \delta_{\min }, \Delta \delta_{\max }$ is the lower limit and upper limit of the relative displacement; $\Delta \delta_{D}$ is the displacement difference between the main girders or the tower under the dead load of the structure; $\Delta C_{\delta}$ is the influence matrix of the displacement difference between the main girders or the tower under unit cable force and counterweight.

2.4. Multiobjective Optimization. Two objective functions ( $U$ and $S$ ) have been established in Section 2.2, which constitutes a multiobjective optimization problem.

There is usually only one optimal solution in singleobjective optimization problems, and the optimal solution can be obtained by relatively simple and commonly used mathematical methods or program toolboxes. However, in the multiobjective optimization problem, objective functions restrict each other. The performance of one objective is often improved at the cost of decreasing the performance of other objectives. It is impossible to have a solution that optimizes all objectives' performance, so for multiobjective optimization problems; the answer is usually a set of noninferior solutions-Pareto solution.

There are two main solutions for solving multiobjective optimization as follows: (1) the intelligent algorithm represented by NSGA-II [21]; (2) the traditional optimization method represented by the weighted coefficient method [15].

The disadvantage of the traditional weighted coefficient optimization method lies in the arbitrariness of the selection of weights. It is difficult for engineers to determine the optimal weighted coefficients, so the resulting design variables have strong arbitrariness. In fact, the arbitrary selection of weight coefficients corresponds to the Pareto optimal solution set in multiobjective optimization.

Assuming that the weight coefficient of the sum of bending energy is $U_{x}$ and the weight coefficient of the sum of weights is $S_{x}$, a single-objective function $P(x)=\left(U / U_{x}\right)+$ $\left(S / S_{x}\right)$ is established following the traditional linear weighted coefficient method. Multiply both sides by $U_{x}$ and suppose $w=\left(U_{x} / S_{x}\right)$, we have

$$
F(x)=U_{x} P(x)=U+\frac{U_{x}}{S_{x}} S=U+w S,
$$

where $F(x)$ only reflects the numerical relationship and does not represent any physical meaning. After the minimum value of the utility function is solved, the design variables should be substituted into the original objective function to have its physical meaning.

As shown in Figure 2, the larger the weight coefficient $w$, the larger the value of $U$ and the smaller the value of $S$. When $w>w_{0}$ (to be determined), the value of the secondary objective function will be zero, and the problem is reduced to the optimization of the bridge cable force without considering the counterweights. When $w$ is very small, $F$ is almost unaffected by $S$ and $U$ will gradually stabilize at $U_{\text {min }}$, which corresponds to the minimum summary of the bending energy that can be found by random weights. When $w=0$, the influence of $S$ disappeared.

In conclusion, the reasonable completion state of asymmetric cable-stayed bridges can be expressed as follows:

$$
\left\{\begin{array}{l}
\min F(X)=\frac{1}{2} X^{T} H X+\left(c^{T}+w \times\left[O_{1 \times n}, I_{1 \times n}\right]\right) X, \\
\text { s.t. } \quad A X \leq b,
\end{array}\right.
$$

where $F(X)$ is the single-objective utility function of quadratic programming form that omits constant terms. It contains the primary objective function $U$ and the secondary objective function $S$. It is worth noting that $w$ is a variable. For different weighted coefficients $w$, different solutions of $F$ $(x)$ will be obtained. After that, a solution of Pareto can be achieved by substituting the solution of $F(x)$ into $U(x)$ and $S$ $(x)$. As long as taking many weighted coefficients, we can get a series of resolutions, forming a whole Pareto solution. $A X \leq b$ is the selected constraint conditions from the 


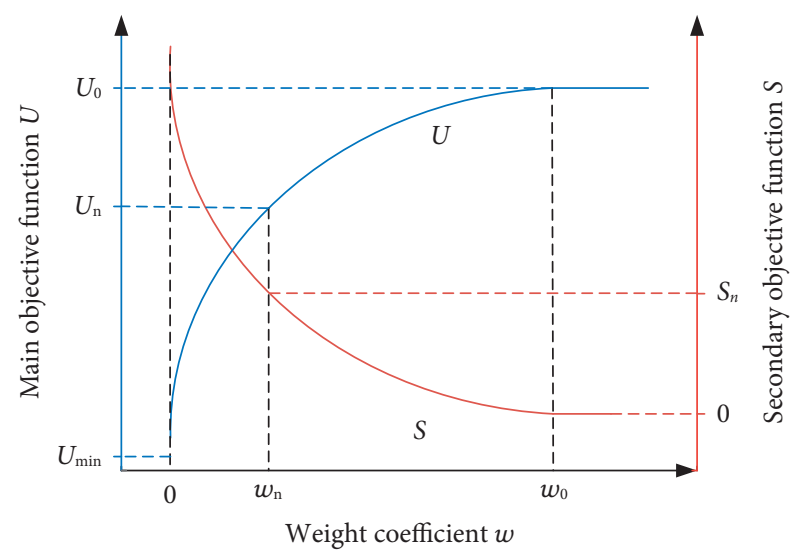

FIgURE 2: Objective function $U / S$ and $w$.

previous section. For example, when considering the constraint of internal force, equation (9) can be expressed as $\left\{\begin{array}{l}M_{X} X \leq M_{\max }-M_{D} \\ -M_{X} X \leq-\left(M_{\min }-M_{D}\right)\end{array}\right.$, so $A$ is $\left[\begin{array}{c}M_{X} \\ -M_{X}\end{array}\right]$ and $b$ is $\left[\begin{array}{c}M_{\max }-M_{D} \\ -\left(M_{\max }-M_{D}\right)\end{array}\right]$.

2.5. Optimization Process. Figure 3 shows the flow chart of the IOM algorithm considering the counterweights. Among them, if all counterweights are excluded from the design variables, then COM without considering the counterweights can be realized simultaneously.

(1) Establish the finite element model of cable-stayed bridge.

(2) Extract the influence vectors of displacement, cable force, and internal force of the cable-stayed bridge under a constant load of the completed bridge. Extract the influence matrix of displacement internal force and cable force of the cable-stayed bridge under the action of unit cable force. Extract the influence matrix of displacement, internal force, and cable force of the cable-stayed bridge under the action of unit counterweight.

(3) Take $T$ as a design variable without considering the counterweights; draw up a reasonable constraint condition; establish a mathematical model of COM and solve.

(4) If the solution $T_{0}$ and $U_{0}$ cannot be solved, modify the constraint conditions and solve it again. If there is a solution, the result of a set of pretension forces is credited as $T_{0}$ and the summary of bending energy is credited as $U_{0}$. If the calculation is not satisfied, modifying the constraint conditions can only arrive at the unsolvable situation. Then, the counterweights must be considered.

(5) Introduce the counterweights; take $X$ as an independent variable. Establish a mathematical model of IOM and solve.

(6) If the solution cannot be solved, modify the constraint conditions and solve it again. If there is a solution, choose the best according to the Pareto curve; the result of a set of pretension forces is credited as $X_{1}$, and the summary of bending energy is credited as $U_{1}$. If the calculation is not satisfied, modifying the constraint again and again until satisfaction.

\section{Numerical Example}

This section introduces a simple numerical model of a cablestayed bridge. The ratio of side span to midspan is 0.55 , showing asymmetry along the bridge. Three different optimization schemes are used for the optimization of reasonable finish dead state: (1) practical method (PM) of bending energy minimum [12], (2) coordinated optimization without considering the counterweights (COM), and (3) integrated optimization method (IOM) considering the counterweights on anchor points. The comparison of three corresponds reasonable finish states is given subsequently.

3.1. Case Description. The simulation model of the cablestayed bridge is established in ANSYS software. The entire structure is symmetrical along the middle of the span. The geometric dimensions and variable numbers of the semistructure are shown in Figure 4. The entire structure is symmetrical along the midspan, so a semistructure finite element model is established. The midspan span is $120 \mathrm{~m}$, and the side span is $55 \mathrm{~m}$. The main tower is $45 \mathrm{~m}$ high above the bridge deck and $15 \mathrm{~m}$ below the bridge deck. Tower and beam are consolidated together. The structural materials of the tower and beam are steel, and the specific material parameters are shown in Table 1.

There are a total of 12 design variables, which are the pretension of 6 cables $(T)$ and the value of 6 counterweights $(W)$. When the length of the stay cable is less than $500 \mathrm{~m}$, the nonlinear geometric effect of the stay cable is not strong, and the correction of the elastic modulus by applying a cable force value close to the target state to the stay cable is sufficiently accurate [20]. In this case, the Ernst formula is used to calculate the elastic modulus reduction when $T=1200 \mathrm{kN}$, and the modified cable elastic modulus is as follows:

$$
E_{\text {tan }}=\frac{E}{1+\left(\left(w L_{x}\right) A / 12 T^{2}\right) E}
$$

3.2. Calculation Process. Under unit weight at each cable point position and the influence vector of the main objective function are shown in Figure 5. The side span counterweights can generally reduce the main objective function, and the return is positive. The midspan counterweights increase the bending energy and is not suitable for configuration. Also, the effect of counterweights at the outside anchor point $W 11$ is the best, and the counterweights should be mainly concentrated on the side span side point in the counterweight design. In long-span cable-stayed bridges, the counterweights are generally arranged on the outside of the 


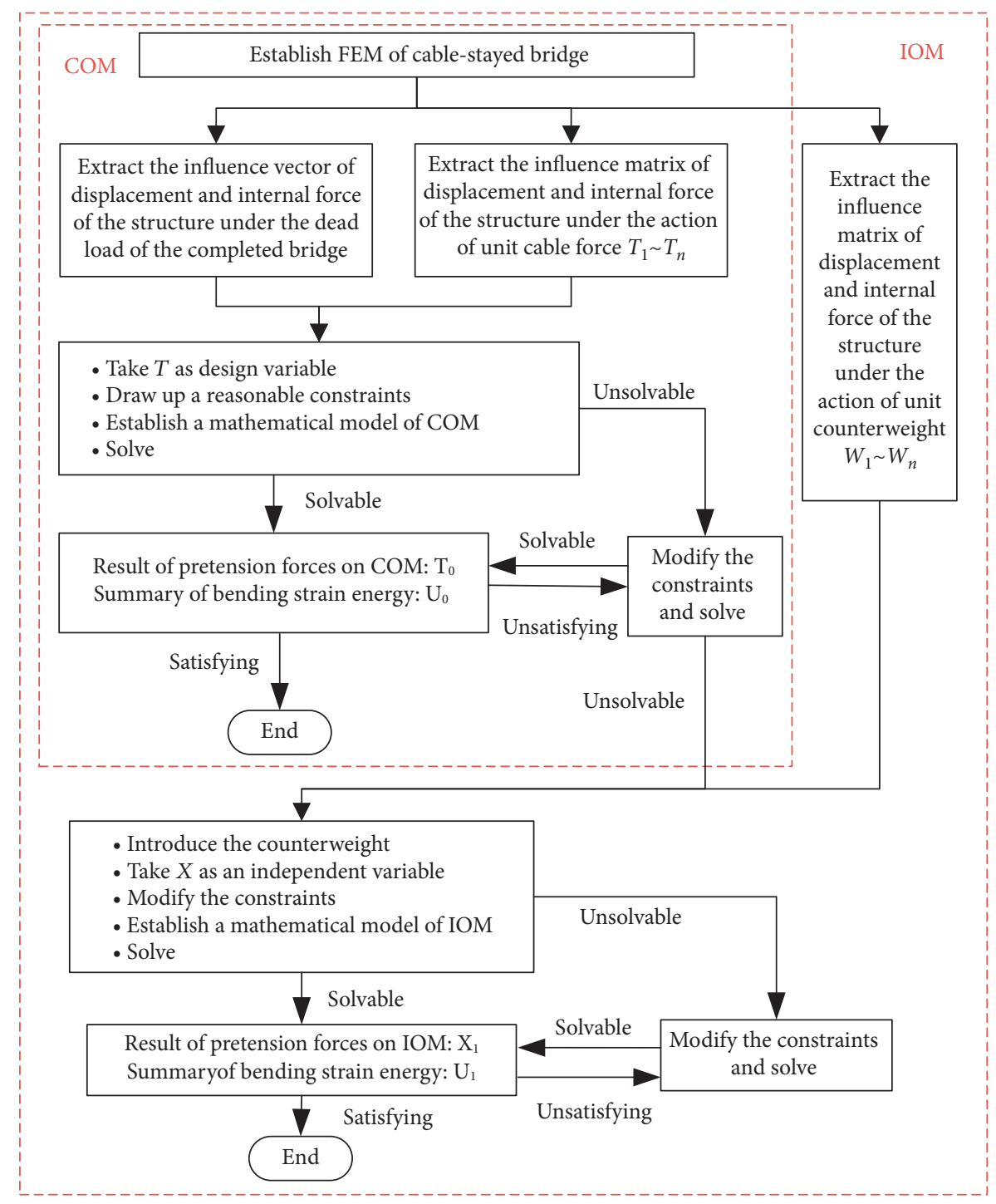

FIgURE 3: Flow chart of IOM.

side span, which can also be explained from the counterweight efficiency in the above discussion.

With $S$ as the independent variable and $U$ as the dependent variable, a Pareto frontier scatters plot can be drawn as shown in Figure 6. The zero position of the counterweight (triangle) is used as the COM optimization result, and the $150 \mathrm{kN}$ position of counterweight (five-pointed star) is the IOM optimization result.

After analysis, it can be found that the single-objective optimization method with the weighted coefficient as the independent variable can also obtain the Pareto objective solution similar to the multiobjective optimization. The theoretical basis is the simplest and easy to be accepted by engineers.

\section{Result Analysis}

The design variable results are shown in Figure 7. The coordinated optimization method does not add counterweights to all positive effect points $(W 11 \sim W 13$ in Figure 4), but only adds one counterweight at $W 11$, the most efficient node. After adding the counterweight, the cable force distribution did not change significantly.

The comparison of structural bending moments is shown in Figure 8. Regardless of whether PM or COM is used, the bending moment of the main girder is essentially the same, but the bending moment at the bottom of the pylon using COM is only half of that in PM, indicating that the stiffness of the pylon in this example is small, and the bending moment changes are more sensitive to the main girder. Compared with the optimization of a cable-stayed bridge without considering counterweights, the IOM significantly improves the bending moment of the outer main girder section of the side span, and at the same time, the bending moment of the bridge tower is almost zero. Noticing the magnitude difference between the bending moments of the pylon, the improvement of the bending moment of the pylon is not significant in Figure 6. The difference of $3 \mathrm{e} 13$ is only $1 / 8$ of the value of COM, which can be 


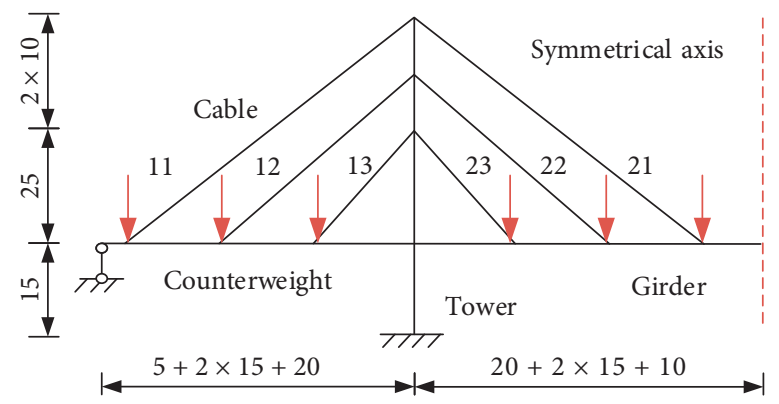

FIgURE 4: Layout of the simple cable-stayed bridge.

TABle 1: Parameter of the simple cable-stayed bridge.

\begin{tabular}{lccc}
\hline & Girder & Column & Cable \\
\hline Iyy $\left(\mathrm{m}^{4}\right)$ & 0.7 & 5.0 & - \\
Area $\left(\mathrm{m}^{2}\right)$ & 2.0 & 4.0 & 0.003 \\
Density $\left(\mathrm{kg} / \mathrm{m}^{3}\right)$ & 2600 & 2600 & 2600 \\
Poisson's ratio & 0.3 & 0.3 & 0.3 \\
Elastic modulus $(\mathrm{Pa})$ & $2.05 e 11$ & $2.05 e 11$ & $2.05 e 11$ \\
\hline
\end{tabular}

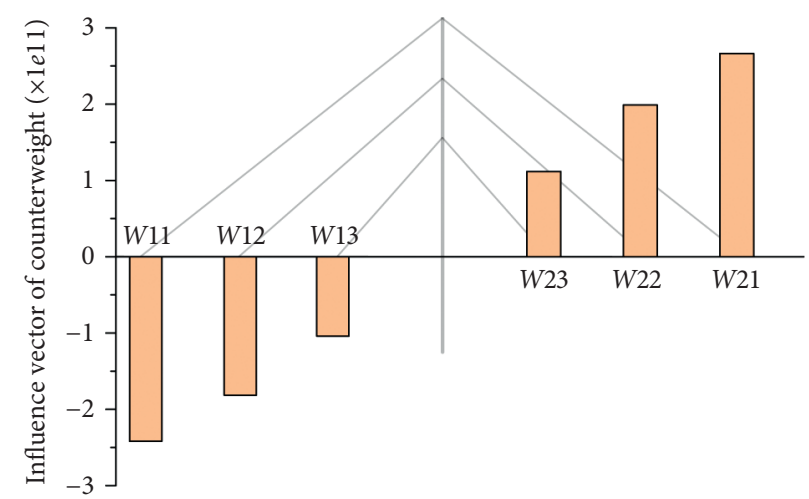

FIGURE 5: Influence vector of counterweight on primary objective function.

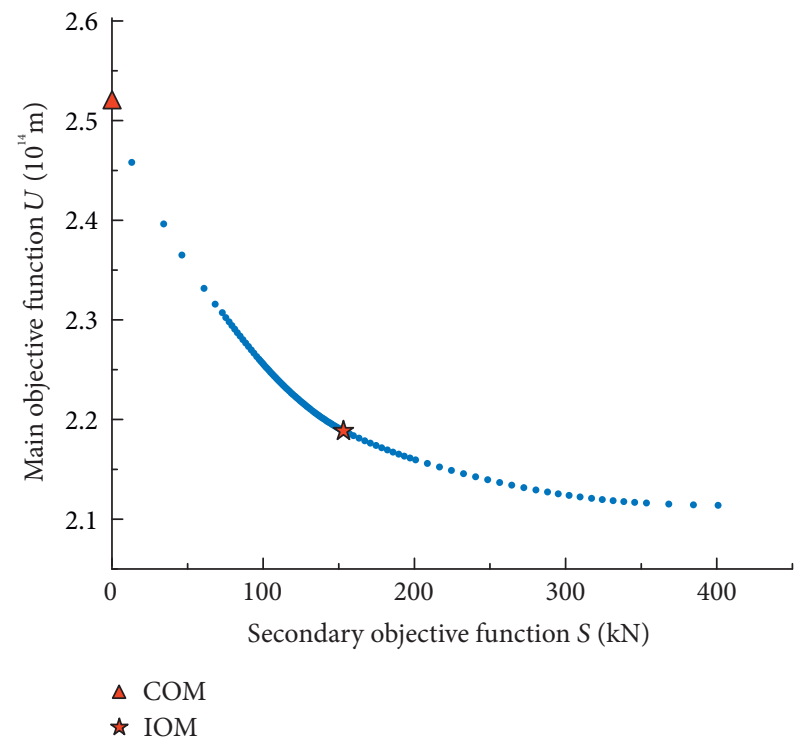

Figure 6: Pareto pioneer point of $U-S$. 


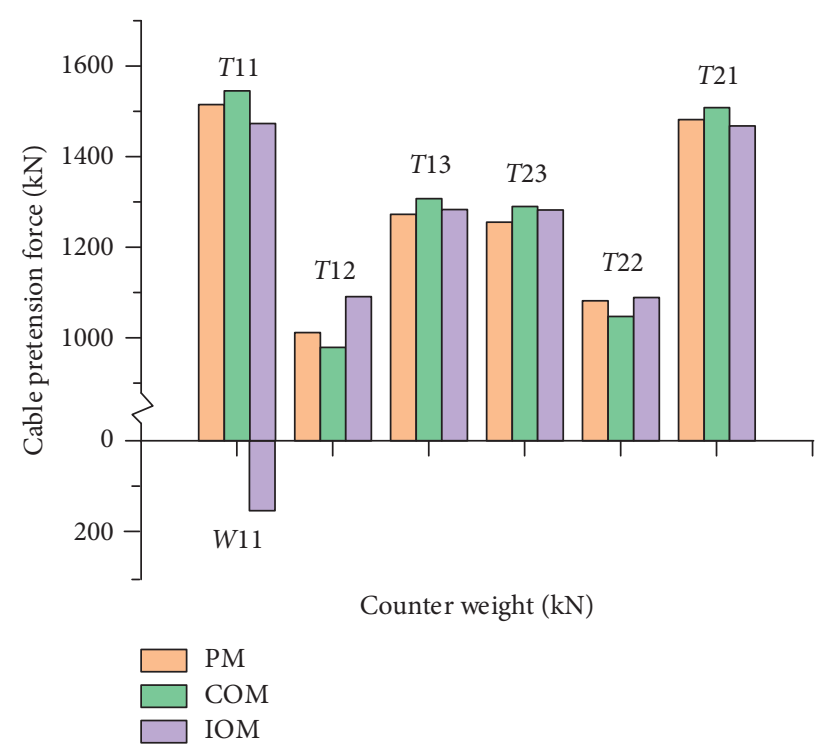

FIGURE 7: Comparison of design variables of simple cable-stayed bridge model.

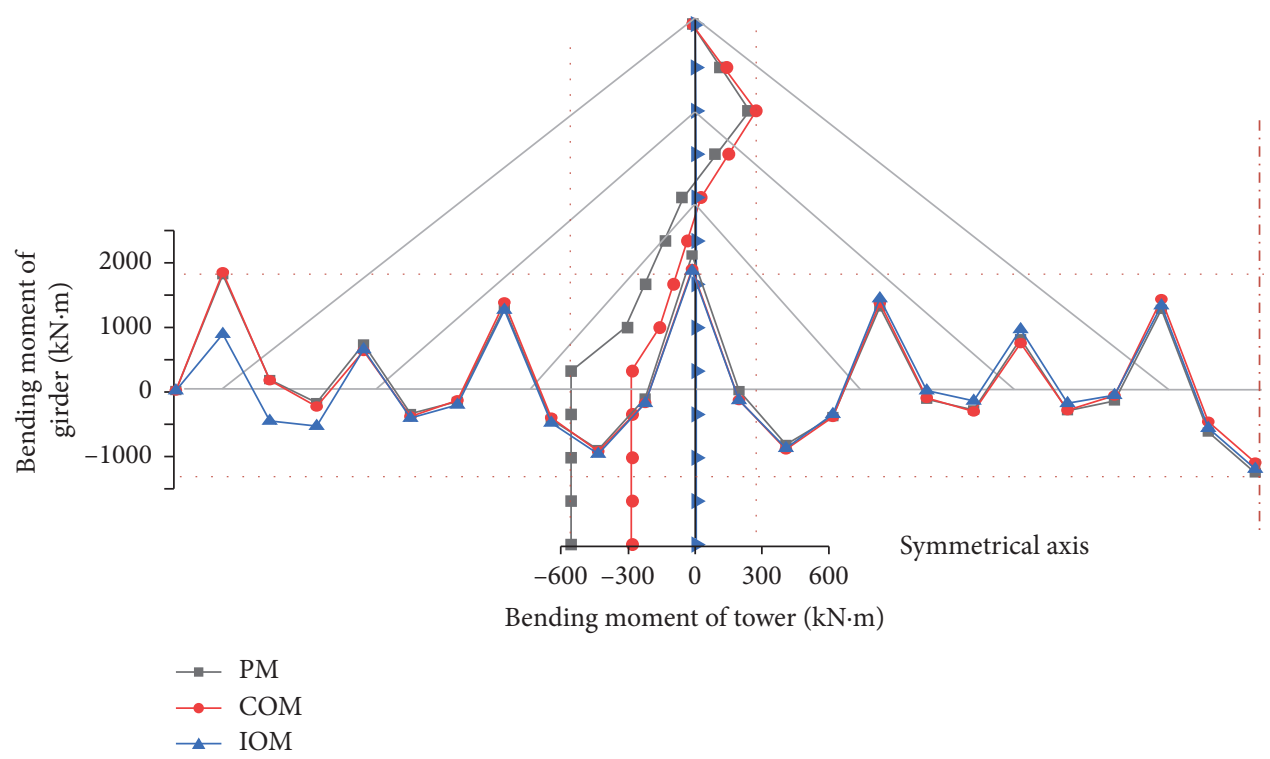

Figure 8: Comparison of bending moment of the simple cable-stayed bridge model.

blamed on the weak stiffness of the tower. The comparison of structural deformation is shown in Figure 9. PM has the largest deformation, followed by COM, and IOM is the smallest. The bending moment and displacement of the bridge tower in the reasonable finish state using IOM are basically zero.

\section{Engineering Application}

5.1. Project Overview. The shape of the main tower of the special-shaped cable-stayed bridge on the Yong-ding River is an arched structure with two-tower columns that are not uniformly inclined. The center lines of the two-tower columns of the bridge tower are 25.1 meters apart along the bridge at the bottom of the tower, and the two-tower columns forming the same tower are not uniformly inclined.
The stay cables are arranged in a harp style with gradual distances, and the distance between the cables on the tower is $2.90 \sim 7.26 \mathrm{~m}$. The vertical height of the main tower above the bridge deck is about 112.195 meters, and the inclination angle of the north tower pillar is about $61.251^{\circ}$. The vertical height of the low tower above the bridge deck is about 76.5 meters, and the south tower pillar inclination angle is about $71.127^{\circ}$. Figure 10 shows the overall layout and cable numbering of Yong-ding River Bridge.

5.2. Finite Element Model. The 3D FEM is established in MIDAS CIVIL. As is shown in Figure 11, there is no symmetrical relationship between the transverse and longitudinal directions, showing a high degree of asymmetry. There are 112 


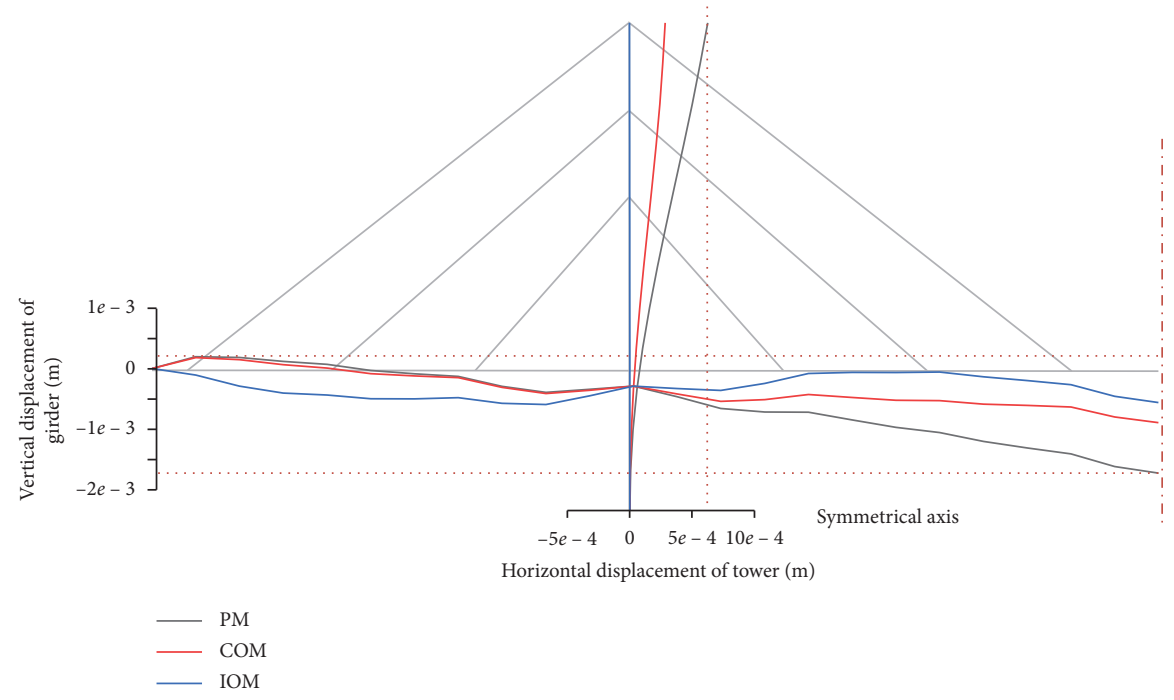

Figure 9: Comparison of displacement of the simple cable-stayed bridge.

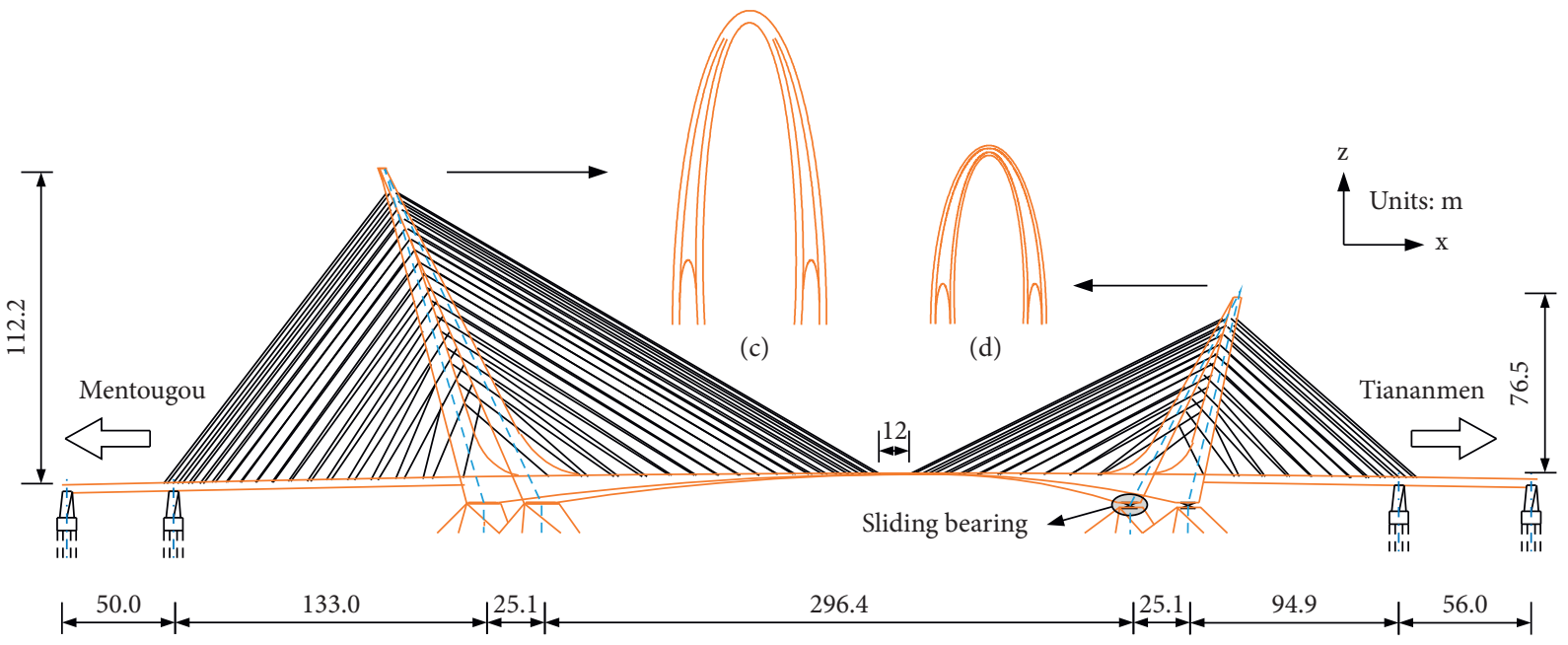

(a)

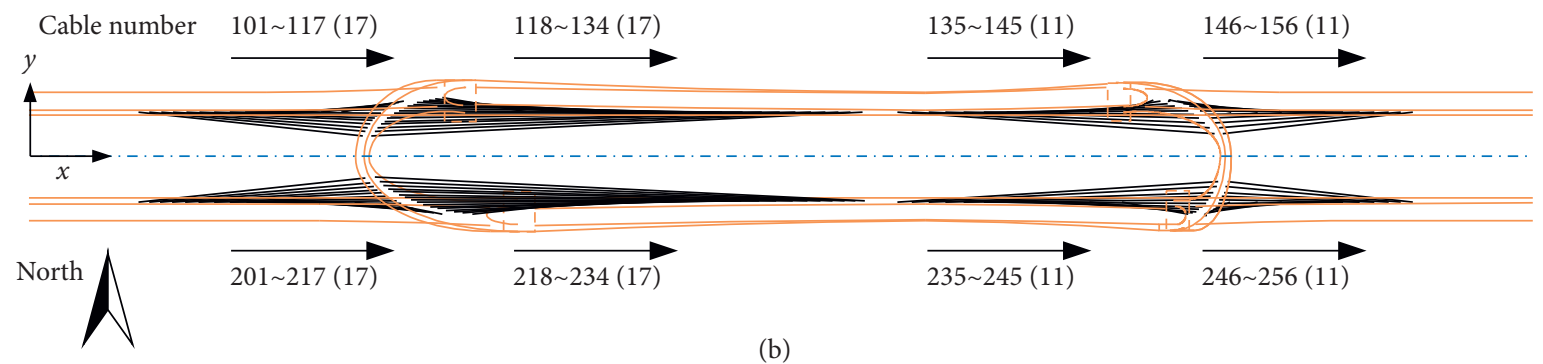

Figure 10: Sketch of the Yong-ding cable-stayed bridge. (a) Main view. (b) Top view. (c) Side view of the high tower. (d) Side view of the low tower.

cables in the bridge, and the correction of Young's modulus is considered as all cables' initial tension being $3000 \mathrm{kN}$.

This bridge is a cable-stayed bridge with a tower-beam consolidation system. The high tower is consolidated with the beam and pier. The low tower is consolidated with the beams, then set with sliding bearings on the pier. The connection of the tower beam, the tower and the pylon support, the main beam node and the stay cable node, and the connection between the pylon node and the stay cable node are all simulated by the rigid connection of "masterslave restraint." The side pier supports are simulated by elastic connections.

The overall structure model has a total of 3857 nodes and 4941 elements. 


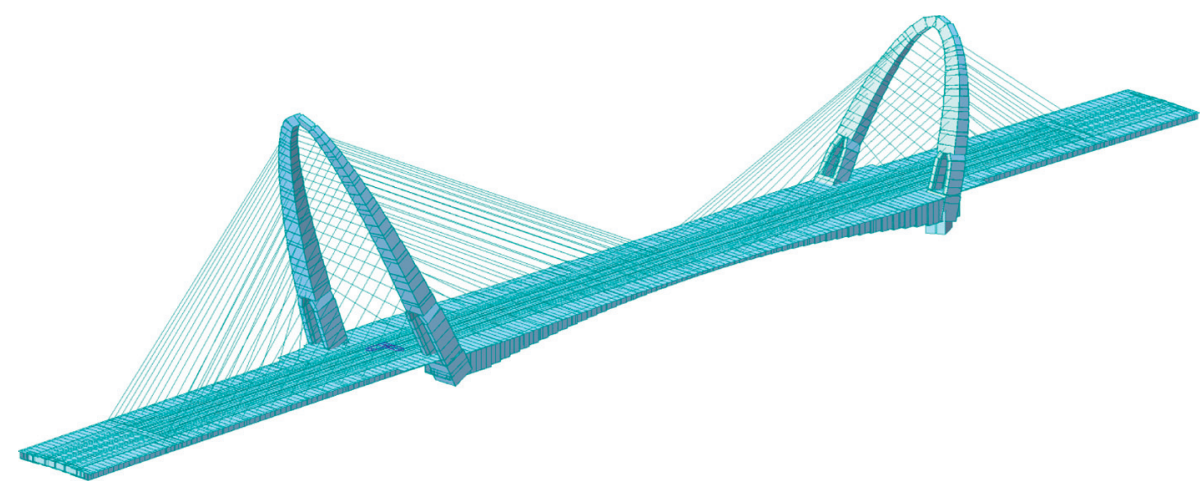

FIgURE 11: FEM of the Yong-ding cable-stayed bridge.

5.3. Integrated Optimization. The design variables are the initial tension of 112 cables and 112 anchor point counterweights, a total of 224 design variables. In complex models, the applicability of the PM method is difficult to guarantee. Therefore, only IOM and COM are compared in this project. The primary objective function selects the sum of the bending strain energy of the north-south main girders and the bridge tower above the bridge deck (excluding the bridge deck moment), and the secondary objective function selects the sum of the counterweight on the anchor points. Similar to Figures 2 and 6, the weight coefficient is set as $10^{13}$ for IOM and $10^{23}$ for COM.

The constraints under several different conditions after adjustments are shown in Table 2. The lower limit of the pretension force constraint is to prevent the cable from being slack, and the upper limit is to prevent the cable from being broken; the uniformity constraint is given a symmetric upper and lower limit based on the trial-calculated cable force, and the limit value of 100 is used here; The counterweights constraint can be given a maximum value.

With COM_1, the maximum displacement of the pylon along the bridge can only be restricted to $0.03 \mathrm{~m}$, and the maximum torsional displacement can only be restricted to $0.08 \mathrm{~m}$, which is very unsatisfactory. However, if the constraints continue to be tightened in COM_2, the algorithm will not converge, indicating that the maximum value problem cannot be solved within these constraints. After considering counterweights, IOM_1 can make it solvable under COM_2's constraints and IOM_2 can continue to tighten the displacement constraint, and the torsion of the bridge deck can even be limited within $0.01 \mathrm{~m}$. The following COM default to COM_1 and IOM default to IOM_2.

\section{Result Analysis}

The design variables obtained by IOM are shown in Figure 12. Due to the special-shaped characteristics of the bridge tower, the cable force distribution on the north and south beams does not show a certain regularity, nor does it increase with the cable length. In the pretension of the cables in the middle span of the north main girder, as the cable length increases, the pretension even shows a decreasing trend.
According to the distribution of counterweights in Figure 5, its role can be summarized in two points: (1) balance the side span and midspan load. Same as Section 3, the side span should be counterweighted relative to the midspan preferentially; (2) balance the spatial effect of the north and south main girders, that is, the midspan counterweights should be staggered on the north or south main beams.

In the cable-stayed bridge of Yong-ding River, counterweights reflect the characteristics of scattered distribution and "dense outside but sparse inside." The counterweights on the north side are concentrated on the side span of the high tower and the midspan of the low tower. The counterweights on the south side are concentrated on the midspan and low span of the high tower except for the two counterweights on the side span of the high tower. The characteristics of staggered counterweights can ensure the effectiveness of the counterweights and at the same time play a certain role in compensating for nonuniformly inclined bridge towers. On the other hand, the weight density of the side span was significantly higher than that of the middle span, which can balance the excessive load of the middle span due to the asymmetric span ratio along the bridge direction.

The vertical displacement of the north-south main girders is shown in Figure 13. Regarding vertical displacement of the main girders, both schemes have been limited to $5 \mathrm{~cm}$. The vertical displacement of the north-south main girders of COM shows the opposite movement trend, and the maximum vertical displacement difference in the same section reaches $7 \mathrm{~cm}$.

After repeatedly adjusting the constraint conditions, it can be found that only considering the adjustment of the cable force cannot constrain the vertical displacement of the north-south main girders within the target range, and the consideration of the counterweights is very necessary. The constraint condition of the torsional displacement difference of the north-south main beam of IOM can be tightened to $[-0.01,0.01]$. It can be found in Figure 14 that the torsional displacement difference is significantly improved compared with the case that the counterweights are not considered.

The maximum values of the remaining parameters of the structure in a reasonable finish state are shown in Table 3. The main objective function $U$ and secondary objective 
TABLE 2: Range of constraint conditions.

\begin{tabular}{lccccc}
\hline Constraints & COM_1 & COM_2 & IOM_1 & IOM_2 & Units \\
\hline Cable force & {$[0.18,0.40]$} & {$[0.18,0.40]$} & {$[0.18,0.40]$} & {$[0.18,0.40]$} & $F_{p k} A \mathrm{kN}$ \\
Uniformity of cable force & {$[-100,100]$} & {$[-100,100]$} & {$[-100,100]$} & {$[-100,100]$} & $\mathrm{kN}$ \\
Vertical displacement of girders & {$[-0.05,0.05]$} & {$[-0.05,0.05]$} & {$[-0.05,0.05]$} & {$[-0.05,0.05]$} & $\mathrm{m}$ \\
Displacement of bridge tower along bridge & {$[-0.03,0.03]$} & {$[-0.02,0.02]$} & {$[-0.03,0.03]$} & {$[-0.02,0.02]$} & $\mathrm{m}$ \\
Relative displacement of North-South girders & {$[-0.08,0.08]$} & {$[-0.01,0.01]$} & {$[-0.08,0.08]$} & {$[-0.01,0.01]$} & $\mathrm{m}$ \\
Counterweights & - & - & {$[0,500]$} & {$[0,500]$} & $\mathrm{kN}$ \\
Solvable & Yes & No & Yes & Yes & - \\
\hline
\end{tabular}

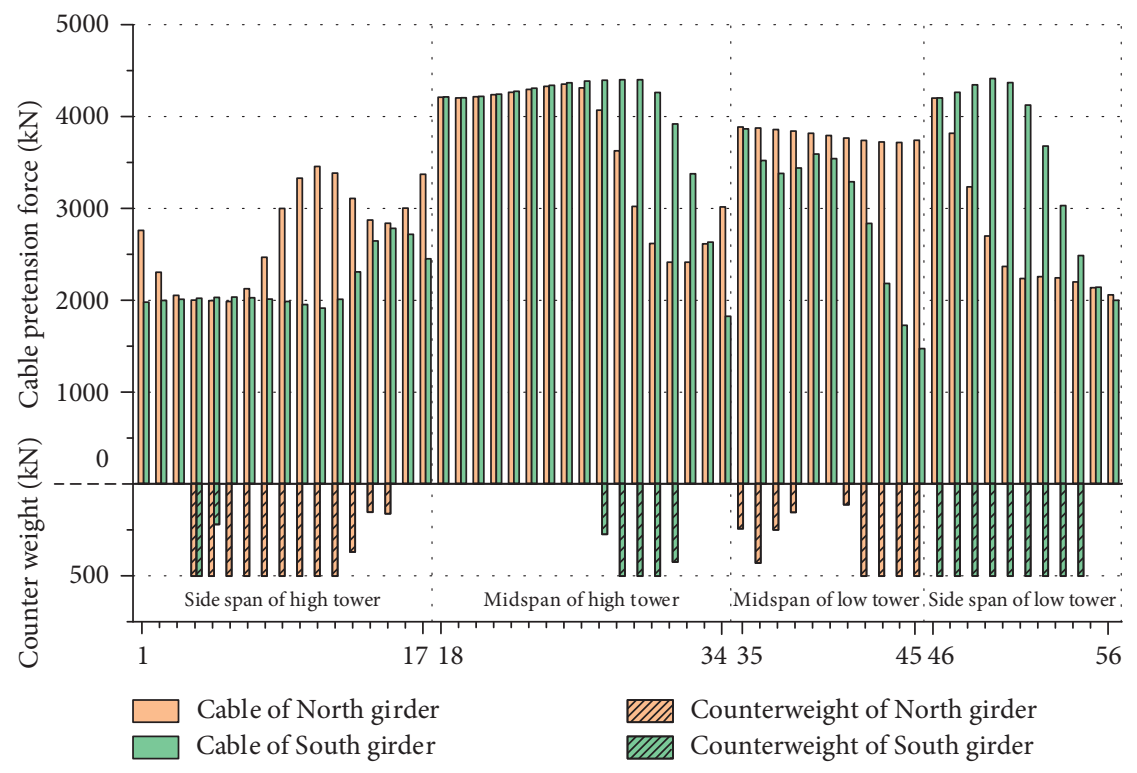

Figure 12: Design variables of girders (cable forces and counterweights).

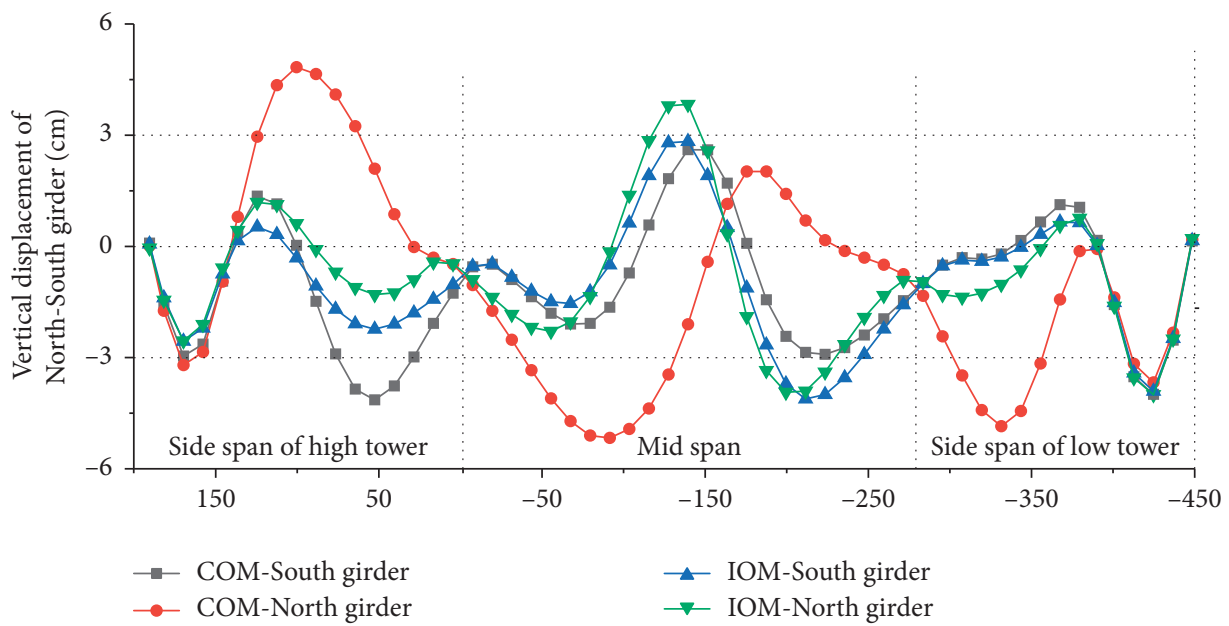

FIGURE 13: Comparison of vertical displacement between main girders.

function $S$ using COM are smaller than the IOM. In other words, the bending moment of the bridge tower and the main beam are smaller reflected in the internal force of the structure. However, observers should not miss a great improvement of the displacement state of the tower along the bridge direction and the main girders. The IOM increases the counterweight dimension, expands the feasible range of the objective function value, tightens the constraint conditions, and limits the bridge tower displacement and the bridge deck torsion within the ideal range. 


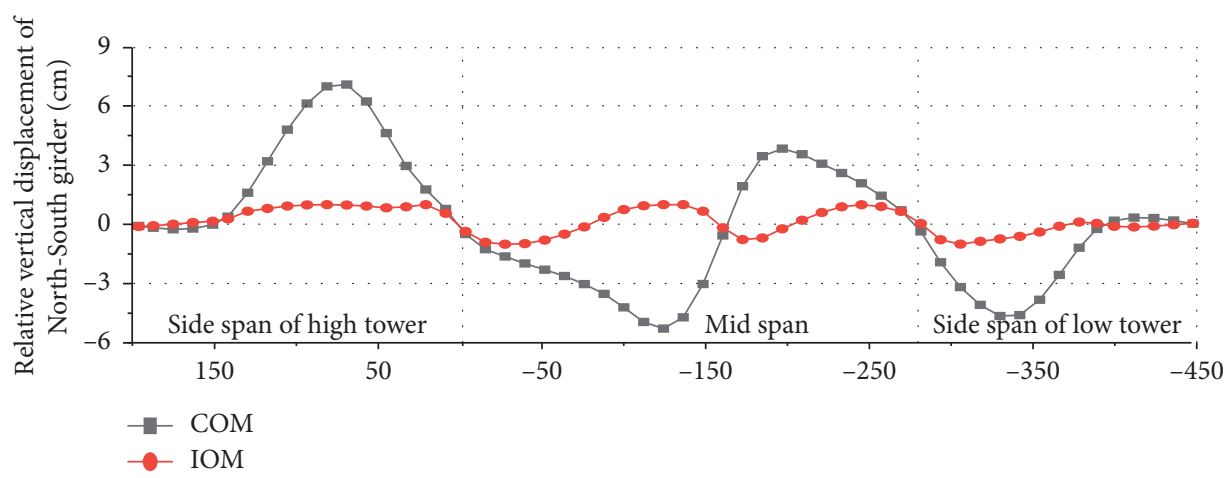

FIGURE 14: Comparison of torsion between main girders.

TABLE 3: Comparison of maximum values of reasonable finished state between COM and IOM.

\begin{tabular}{|c|c|c|c|}
\hline Evaluation index & $\mathrm{COM}$ & IOM & Units \\
\hline Main objective function $U$ & $8.62 E+15$ & $9.31 E+15$ & $\mathrm{kN} \cdot \mathrm{m}$ \\
\hline Secondary objective function $S$ & 0 & $3.16 E+07$ & $\mathrm{kN}$ \\
\hline Maximum bending moment of main tower & $4.90 E+07$ & $5.38 E+07$ & $\mathrm{kN} \cdot \mathrm{m}$ \\
\hline Maximum bending moment of low tower & $5.84 E+07$ & $4.80 E+07$ & $\mathrm{kN} \cdot \mathrm{m}$ \\
\hline Maximum bending moment of north girders & $5.24 E+08$ & $4.96 E+08$ & $\mathrm{kN} \cdot \mathrm{m}$ \\
\hline Maximum bending moment of south girders & $4.00 E+08$ & $4.46 E+08$ & $\mathrm{kN} \cdot \mathrm{m}$ \\
\hline Maximum displacement of main tower along the bridge & 0.03 & 0.01 & $\mathrm{~m}$ \\
\hline Maximum displacement of low tower along the bridge & 0.03 & 0.01 & $\mathrm{~m}$ \\
\hline
\end{tabular}

\section{Conclusions}

In order to solve the reasonable finish state of an asymmetric cable-stayed bridge, this paper proposes the integrated optimization method (IOM) considering the counterweights on the anchor point:

(1) Compared with the hill-climbing algorithm, IOM has high efficiency and good convergence. The assumption of counterweights on anchor point is applicable to all cable-stayed bridges, and it can be easily converted to uniform weight based on simple structural mechanics.

(2) The counterweights are of great benefit to the improvement of the reasonable finish state of the cable-stayed bridge. IOM introduces the counterweights dimension to expand the optimization space and can obtain a better bridge state than COM. By changing the weight coefficient, IOM can offer lots of Pareto solutions (COM included) to choose.

(3) When the constraints are not strict, the main objective function using IOM is better than COM. In the simple cable-stayed bridge model comparison case, the IOM can automatically arrange the counterweights at the most efficient cable point, without manually judging the loading position, which can greatly improve the structural state.

(4) When the constraints are strict, IOM uses a small increase in the objective function in exchange for the tightening of the constraint conditions, which improves the displacement state of the structure makes the algorithm continue to converge. In the study of the reasonable completion status of the Yong-ding River, COM cannot find a satisfactory solution under the constraint condition but IOM can do it better.

\section{Data Availability}

The data in this manuscript are obtained from the finite element model built.

\section{Conflicts of Interest}

The authors declare that there are no conflicts of interest regarding the publication of this paper.

\section{Acknowledgments}

The authors gratefully acknowledge the financial support of the China Academy of Railway Sciences Corporation Limited.

\section{References}

[1] J. Guo, W. Yuan, X. Dang, and M. S. Alam, "Cable force optimization of a curved cable-stayed bridge with combined simulated annealing method and cubic B-Spline interpolation curves," Engineering Structures, vol. 201, 2019.

[2] Y.-C. Sung, D.-W. Chang, and E.-H. Teo, "Optimum posttensioning cable forces of Mau-Lo Hsi cable-stayed bridge," Engineering Structures, vol. 28, no. 10, pp. 1407-1417, 2006.

[3] J. J. Jorquera-Lucerga, J. A. Lozano-Galant, and J. Turmo, "Structural behavior of non-symmetrical steel cable-stayed bridges," Steel and Composite Structures, vol. 20, no. 2, pp. 447-468, 2016. 
[4] L. W. Zhang and R. J. Xia, "The reasonable finished dead state research of partially earth-anchored cable-stayed bridge," Presented at the Advances in Civil Engineering, DurntenZurich, vol. 255-260, 2011.

[5] C. Song, R. Xiao, and B. Sun, "Optimization of cable pretension forces in long-span cable-stayed bridges considering the counterweight," Engineering Structures, vol. 172, pp. 919-928, 2018.

[6] A. M. B. Martins, L. M. C. Simões, and J. H. J. O. Negrão, "Optimization of cable-stayed bridges: a literature survey," Advances in Engineering Software, vol. 149, Article ID 102829, 2020.

[7] D. Jie, Q. Feng-jiang, D. Jin, and C. Yong-rui, "Review on cable force optimization method for cable-stayed bridge in completed bridge state," China Journal of Highway and Transport, vol. 32, no. 05, pp. 17-37, 2019.

[8] P. H. Wang, T. C. Tseng, and C. G. Yang, "Initial shape of cable-stayed bridges," Computers \& Structures, vol. 46, no. 6, pp. 1095-1106, 1993.

[9] D. W. Chen, F. T. K. Au, L. G. Tham, and P. K. K. Lee, "Determination of initial cable forces in prestressed concrete cable-stayed bridges for given design deck profiles using the force equilibrium method," Computers \& Structures, vol. 74, no. 1, pp. 1-9, 2000, in English.

[10] L. Peng, X. Ru-cheng, and Z. Xue-song, "Practical method of optimization of cable tensions for cable-stayed bridges," Journal of Tongji University (Natural Science), vol. 11, pp. 1270-1274, 2003.

[11] D. Janjic, M. Pircher, and H. Pircher, "The unit load method some recent applications," Presented at the Advances in Steel Structures, vol. 1-2, Hong Kong, China, 2002.

[12] J.-h. Li, D.-m. Feng, A.-q. Li, and H.-h. Yuan, "Determination of reasonable finished state of self-anchored suspension bridges," Journal of Central South University, vol. 23, no. 1, pp. 209-219, 2016.

[13] M. M. Hassan, A. O. Nassef, and A. A. El Damatty, "Determination of optimum post-tensioning cable forces of cablestayed bridges," Engineering Structures, vol. 44, pp. 248-259, 2012.

[14] M.-H. Ha, Q.-A. Vu, and V.-H. Truong, "Optimum design of stay cables of steel cable-stayed bridges using nonlinear inelastic analysis and genetic algorithm," Structures, vol. 16, pp. 288-302, 2018, in English.

[15] R. T. Marler and J. S. Arora, "The weighted sum method for multi-objective optimization: new insights," Structural and Multidisciplinary Optimization, vol. 41, no. 6, pp. 853-862, 2010, in English.

[16] Z. Jaouadi, T. Abbas, G. Morgenthal, and T. Lahmer, "Single and multi-objective shape optimization of streamlined bridge decks," Structural and Multidisciplinary Optimization, vol. 61, no. 4, pp. 1495-1514, 2020.

[17] W. A. Bennage and A. K. Dhingra, "Single and multiobjective structural optimization in discrete-continuous variables using simulated annealing," International Journal for Numerical Methods in Engineering, vol. 38, no. 16, pp. 2753-2773, 1995.

[18] S. E. H. A. M. Zarbaf, M. Norouzi, R. J. Allemang, V. J. Hunt, and A. Helmicki, "Stay cable tension estimation of cablestayed bridges using genetic algorithm and particle swarm optimization," Journal of Bridge Engineering, vol. 22, no. 10, 2017, in English.

[19] R. E. Perez and K. Behdinan, "Particle swarm approach for structural design optimization," Computers \& Structures, vol. 85, no. 19-20, pp. 1579-1588, 2007.
[20] T.-Y. Lee, Y.-H. Kim, and S.-W. Kang, "Optimization of tensioning strategy for asymmetric cable-stayed bridge and its effect on construction process," Structural and Multidisciplinary Optimization, vol. 35, no. 6, pp. 623-629, 2008.

[21] K. Deb, A. Pratap, S. Agarwal, and T. Meyarivan, "A fast and elitist multiobjective genetic algorithm: NSGA-II," IEEE Transactions on Evolutionary Computation, vol. 6, no. 2, pp. 182-197, 2002. 